\title{
Research on the Innovation of Police Physical Fitness Teaching Method in Public Security College
}

\author{
Fan Zhang \\ School of Police Skills and Tactics, Nanjing Forest Police College, Nanjing 210023, China. \\ Zhangfan@nfpc.edu.cn
}

\begin{abstract}
By using the methods of documentation, expert interview, questionnaire survey and logical analysis, this paper investigates and analyses the current predicament of physical fitness teaching in public security colleges. It is suggested that we should change our teaching concepts, construct a diversified teaching method system of police physical fitness, and pay attention to actual combat, to improve the effectiveness of police physical ability training. In this way, to meet the actual needs of the reform of physical training curriculum in public security colleges, and to provide theoretical reference for the development of physical training in public security colleges.
\end{abstract}

Keywords: Public security college; Police fitness; Physical Training; Teaching method.

\section{Introduction}

Physical fitness plays a vital role in police work, which is related to the professional working ability and physical and mental health of the police, and is also the key to police training. public security colleges shoulder the important responsibility of the state to train the people's police. The physical fitness of their students is the basis of police sports skills, and the basis of effectively guaranteeing the students' learning of defense control, police tactics, weapon use, climbing and other skills. However, the physical fitness training of public security colleges still stays at the level of experience teaching. There is a serious disconnection between the actual work needs of public security and the needs of police physical fitness.

In other words, due to the influence of traditional teaching concepts, there are still many practical problems to be solved urgently in Police Physical Fitness Teaching in public security colleges. Among them, the obsolete and single teaching method is representative, which has become an important factor affecting and restricting the training and development of police physical fitness of students in public security colleges [1]. In view of this, strengthening the innovation of police physical fitness teaching methods in public security colleges will not only help to improve the effectiveness of police physical fitness teaching, but also play a particularly important role in promoting and guaranteeing the development of students' comprehensive police ability in public security colleges.

\section{Innovative Significance of Police Physical Fitness Teaching Method}

Police physical fitness refers to the specific physical fitness required by the police profession. It mainly supports and guarantees the working state with strong intensity, long duration and short-term explosive force. It is the essential quality and ability of the police, and the basic condition for the police to perform their social duties. The main purpose of setting up police physical training courses in public security colleges is not only to make necessary physical preparation for teaching police actual combat skills, but also to build up the foundation for the future career development of students in public security colleges. In the traditional teaching of police physical training, physical training instructors basically adopt the method of "content arrangement, key points explanation, student practice, teacher summary", which is stylized and single. It will have a serious impact on the effect of students' physical training [2]. For example, in the teaching of endurance training, the teaching method adopted by the instructor is to bring the students to the playground. After simple teaching requirements and precautions, the students carry out the endurance training of running circles, which leads to the dull teaching atmosphere. In view of this, it is of great practical significance to strengthen the innovation of the existing police physical training teaching methods. 


\subsection{Helpful to Improve the Accuracy of Police Physical Training.}

Police physical fitness is an important part of police professional quality and ability, and it is the basic guarantee of fulfilling social responsibility and realizing professional development. Therefore, improving the accuracy of police physical training has important practical value. This requires police physical training instructors to create and implement targeted teaching methods in line with the principle of "actual combat". For example, changing the traditional endurance training into "pursuit and evasion training" with practical significance not only meets the requirements of actual combat, but also greatly improves the pertinence of endurance training, which has an important role in promoting the development of physical fitness of students in public security colleges.

\subsection{Satisfying the Diversified Development Demand of Students' Police Physical Fitness.}

Due to the influence of their own quality foundation and self-development orientation, the development needs of police physical fitness of students in public security colleges have diversified characteristics [3]. For example, students with outstanding endurance quality have a strong demand for developing their explosive power, while students with outstanding strength quality have a certain development demand for their sensitivity and flexibility. In view of this, instructors are required to abandon traditional teaching concepts and design targeted teaching methods according to the characteristics of different training projects and students' different development needs, in order to achieve a balanced development of students' police physical fitness and ability.

\subsection{Creating a Good Atmosphere for Police Physical Training.}

Physical fitness training is dull and arduous. It requires trainers to have good will quality and active and independent training consciousness. Police physical training is a compulsory course for students in public security colleges. Therefore, how to effectively improve the dull and arduous state of police physical training and create a good teaching atmosphere through the innovation of teaching methods is necessary. On the one hand, the novelty of teaching methods makes students present a new feeling from sensory perception to psychological experience. On the other hand, students' self-development needs are met to improve their satisfaction with physical training teaching, which effectively improves the boring teaching atmosphere caused by the single traditional teaching methods.

\subsection{Promoting the Innovative Development of Police Physical Fitness Teaching.}

Teaching methods are the main means to transfer knowledge and cultivate skills. The rationality of teaching methods will have an important impact on the improvement of teaching effect and the realization of teaching objectives. At present, our country is in the decisive stage of building a welloff society in an all-round way. Therefore, it is the primary goal of public security work to put forward new requirements for public security work, improve the overall quality of the public security team and maintain the healthy and harmonious development of society. In view of this, public security colleges are required to actively adapt to the new social development situation and carry out targeted optimization and innovation of the police physical training curriculum system. Because the teaching method is the main means to implement the teaching policy and achieve the teaching goal [4]. Therefore, the innovation of teaching methods plays a leading role in the optimization and innovation of teaching system, and it is an important way to innovate teaching system. Strengthening the innovation of police physical training teaching methods in public security colleges plays an important role in promoting the innovation of police physical training teaching system in public security colleges in the new era.

\section{Innovative Strategies of Police Physical Fitness Teaching Method}

As the main position of training reserve police officers, public security colleges at all levels should adapt to the needs of the situation and make necessary adjustments and supplements in the curriculum, teaching methods, teaching quantity and assessment of students' physical training courses. In order to ensure that students lay a good physical foundation in school, grasp the necessary physical exercise 
methods and means, establish the awareness of lifelong sports, develop lifelong sports habits. To provide a reliable guarantee for training and transporting more excellent police force at the grassroots level.

\subsection{Changing Teaching Concepts and Constructing a Diversified Teaching Method System.}

The innovation of teaching methods needs the guidance and standardization of corresponding teaching concepts. Therefore, in the teaching of police physical training in public security colleges, the most important condition for the innovation of teaching methods lies in the change of traditional teaching concepts. This requires physical training instructors to establish innovative principles and innovative orientations of police physical training teaching methods in accordance with the professional characteristics of the police and around the new training objectives of Police Colleges in the new era. In order to ensure the accuracy and effectiveness of teaching method innovation, we should pay attention to the specific requirements of different training projects to develop targeted teaching methods, and construct a diversified teaching method system of police physical training that highlights adaptability and effectiveness. Only in this way can we lay a solid foundation and provide necessary guarantees to ensure the overall effect of police physical fitness teaching.

\subsection{Emphasizing the Actual Combat and Improve the Effectiveness of Physical Training.}

The purpose of the police academy is to actively explore the education and training mode close to the actual combat, cultivate more talents to meet the needs of the actual combat, and make greater contributions to improving the overall quality and combat effectiveness of the police force [5]. Therefore, as one of the compulsory courses in public security colleges, it is of great practical value to strengthen the innovation of traditional teaching methods with the aim of "conforming to actual combat". Therefore, police physical training instructors should pay attention to the study of diversified teaching methods, such as situational teaching method, cooperative teaching method, open teaching method and practical training teaching method. At the same time, combining with the police law enforcement cases, the author seeks to fit the physical training perspective of the actual combat police, and designs the teaching methods that highlight the characteristics of the actual combat, so as to ensure the effectiveness of the physical training teaching of the police.

\subsection{Implementing the Model of "Two Training and One Examination" in Physical Training.}

"Two training" refers to physical training courses and extracurricular physical training. "One examination" means to take a physical examination every semester, and take the test results as the basis for evaluating awards and excellence. Physical training is the main battlefield of physical training. Teachers should pass on theoretical knowledge and scientific training methods of physical training to students in limited time, and try their best to improve some skills, tactics and physical qualities urgently needed by police in practical work. Extracurricular physical training is under the leadership of student management department, and its physical training is an important part of student management assessment. At the same time, physical instructors participate in counseling, and take into account the corresponding workload. The assessment results of the counseling classes are linked to the year-end evaluation [6]. This can mobilize the enthusiasm of student managers and instructors for extracurricular physical training, and ensure the effectiveness of extracurricular physical training. Reasonable assessment contents should be formulated in the assessment process, including not only the contents of physical fitness assessment, but also the contents of psychological quality, body shape, physical function, theoretical knowledge of physical fitness and related skills and tactics. Establish a reasonable and scientific evaluation index system, which will be assessed by the Police Sports Examination Committee every semester, record the results of the assessment in the files, and establish a police physical fitness monitoring system. It is suggested that public security colleges should try to increase the class hours of physical fitness courses, such as setting up a certain class hours of physical fitness training courses at the same time of skill and tactics courses, so as to strengthen the physical needs of skills and tactics courses, and also to add specialized physical fitness training in skills and tactics courses to ensure the learning effect. 


\section{Summary}

Police physical fitness is a necessary condition for the training and development of comprehensive police skills of students in public security colleges, and a basic guarantee to meet their future professional needs. Therefore, under the guidance of the development concept of "conforming to actual combat", strengthening the innovation of traditional police physical training teaching methods and combining actual combat with physical training organically will not only help to create an active, tense and stimulating teaching atmosphere, but also guide and promote students' actual combat experience. At the same time, it can effectively improve the accuracy of police physical training, enhance students' attention to combat-type police physical training, and form a good sense of participation. Furthermore, it lays a solid foundation for the comprehensive development of police actual combat skills.

\section{Acknowledgements}

This research was financially supported in part by the 13th Five-Year plan project of Jiangsu Education Science under Grant C-c/2018/01/11, in part by Jiangsu Qing Lan Project under Grant 2017 (Excellent Teaching Team of NFPC), in part by Overseas Research and Study Project of Excellent Young and Middle-aged Teachers in Colleges of Jiangsu Province of 2018.

\section{References}

[1]. WANG Liheng. The Discussion of the Essence and Related Concepts of Police Sports. Journal of Hubei Open Vocational College. Vol. 32 (2019) No. 15, p. 129-152.

[2]. HUANG Jiashan, WANG Wei. Research on the Plight and Countermeasures of the Development of Physical Training of the Students in Police Colleges. Journal of Military Physical Education and Sports. Vol. 36 (2017) No. 2, p. 37-39.

[3]. YU Jingrong. Research on the Reform of Enrollment Mode in Police College. Journal of Liaoning Police Academy. Vol. 19 (2017) No. 3, p. 112-115.

[4]. LIU Hongfu. The Countermeasure and Research about Students' Physical Training of Police Colleges in Jilin Province. Journal of Harbin Institute of Physical Education. Vol. 35 (2017) No. 1, p. 67-70.

[5]. LUO Weidong, YUAN Zhiliang. Research on Police College Police Physical Education and Training Innovation. The Guide of Science \& Education. Vol. 12 (2016) No. 1, p. 33-35.

[6]. SONG Luyi. A Study on the Learning and Evaluation Mode Reform of Physical Training Courses in Public Security Colleges and Universities. Journal of Liaoning Police Academy. Vol. 10 (2013) No. 4, p. 87-93. 